\title{
A EVOLUÇÃO DO CONCEITO DE GOVERNANÇA NA UNIÃO EUROPEIA E OS MECANISMOS PARA SUA EFETIVAÇÃO
}

\section{THE EVOLUTION OF THE CONCEPT OF GOVERNANCE IN THE EUROPEAN UNION AND MECHANISMS FOR ITS EFFECTIVENESS}

\author{
João Ricardo Fidalgo de Moura \\ Bacharel em Direito pela Universidade Federal de Minas Gerais (UFMG), Pós-Graduando \\ em Direito Processual pela Pontifícia Universidade Católica de Minas Gerais (PUC- \\ Minas). Advogado. Email: fidalgo_cm@yahoo.com.br \\ Jamile Bergamaschine Mata Diz \\ Professora da Faculdade de Direito da Universidade Federal de Minas Gerais (UFMG). \\ Professora da UIT-MG Brasil. Doutora em Direito Público/Direito Comunitário pela \\ Universidad Alcalá de Henares - Madrid. Assessora Jurídica do Setor de Assessoria \\ Técnica da Secretaria do MERCOSUL - Montevidéu (período: 2008-2009). Mestre em \\ Direito pela UAH, Madrid Master en Instituciones y Políticas de la UE - UCJC/Madrid. \\ Email:jmatadiz@yahoo.com.br
}

Giovani Clark

Professor da Graduação e da Pós-Graduação da Pontifícia Universidade Católica de Minas Gerais (PUC Minas). Docente da Faculdade de Direito da Universidade Federal de Minas Gerais (UFMG) Mestre e Doutor em Direito Econômico pela UFMG. Email: giovaniclark@gmail.com

Recebido em: 13/10/2016

Aprovado em: 02/12/2016

Doi: $10.5585 / \mathrm{rdb} . \mathrm{v} 15 \mathrm{i} 6.499$

RESUMO: Em seu início institucional, o processo de integração entre os Estados Membros da União Europeia ocorreu sem contar com mecanismos que levassem em consideração os interesses dos cidadãos europeus. Apontou-se então a necessidade de corrigir o déficit democrático, a partir, sobretudo, do redimensionamento dos instrumentos de garantia da governança em sede supranacional. A ineficácia recorrente das decisões tomadas pelas instituições da União Europeia parece comprovar o alijamento dos cidadãos europeus no processo de tomada de decisões. Desde o Tratado da Comunidade Europeia do Carvão e do Aço em 1951 até o Tratado de Lisboa em 2009, vislumbra-se que a preocupação genuína com métodos de governança consiste em fenômeno recente na União Europeia. Se, por um lado, várias tentativas de fomento à participação cidadã já são levadas a cabo em sede supranacional, por outro, é certo também que os desafios em tal seara são muitos, inclusive quanto ao modo de interpretação e mise-en-oeuvre dos instrumentos legais colocados à disposição dos cidadãos europeus para participarem efetivamente das decisões da União.

Palavras-Chave: União. Integração. Interesses. Governança. Participação. Democracia. 


\begin{abstract}
In its institutional beginning, the process of integration among Member States of the European Union happened without properly considering the interests of European citizens. It was then noticed the necessity of revise the democratic deficit, mainly from the re-dimension of the instruments of governance stated in supranational level. The recurrent inefficacy of the decisions taken by the European Union institutions seems to prove the lack of participation of European citizens when structuring decisions. From the Treaty establishing the European Coal and Steel Community in 1951 to the Treaty of Lisbon, it resembles that the genuine worry with methods ensuring governance consists in a recent phenomenon in the normative praxis of the European Union. If, from one side of view, many attempts in order to guarantee citizen participation have already been taken in supranational level, from another, it is also true that the challenges in such field are tremendous, including the one related to the interpretation method and mise-en-oeuvre of legal instruments available to European citizens to influence decisions of Union institutions.
\end{abstract}

Keywords: Union. Integration. Interest. Governance. Participation. Democracy.

SUMÁRIO: Introdução; 1. Uma análise da governança a partir da multiplicidade de conceitos e a integração estatal; 2. A governança na União Europeia: do Livro Branco ao Tratado de Lisboa; 2.1. A governança e sua previsão nos Tratados fundacionais; 2.2. A influência da governança na conformação da institucionalidade europeia; 3. A aplicação dos postulados da governança pelo Tribunal de Justiça da União Europeia: o caso do glifosato e o direito de participação; Conclusão. Agradecimentos; Referências Bibliográficas.

\title{
INTRODUÇÃO
}

A integração estatal deve ser entendida como um movimento constante e dialético onde se conjugam forças antagônicas, mas nem por isso excludentes. As dificuldades inerentes a qualquer tipo de associação interestatal, especialmente aquelas que pretendem forjar laços mais estreitos de união, não podem ser utilizadas pelos Estados partícipes, de forma individual, para sobrepujar os esforços na criação de um processo pautado em princípios e valores comuns.

Desde a criação dos processos de integração estatal, na década de 50, os movimentos de aproximação e tensão podem ser considerados, em maior ou menor medida, fruto das tentativas de negociação por parte dos Estados componentes deste projeto integracionista. Não obstante, não se deve esquecer que a integração deve ser feita para e em nome dos cidadãos, destinatários finais de qualquer integração. Nesse sentido, a necessidade de serem criados instrumentos para que a participação dos mesmos ocorra de modo efetivo e transparente deu lugar à discussão sobre aspectos inerentes à governança, de modo a inter-relacioná-la com o fortalecimento da democracia.

O objetivo do presente trabalho será analisar justamente a correlação entre governança, participação e democracia nos processos de integração, especialmente no caso da União Europeia, de modo a verificar em que medida as políticas e instituições voltadas para o aperfeiçoamento dos instrumentos de participação, inseridas na concepção de governança, reforçaram o caráter democrático e legitimador da integração interestatal.

A metodologia de trabalho deverá centrar-se nos aspectos principais estabelecidos para uma pesquisa baseada na interdisciplinaridade do tema ao envolver a discussão da participação num espaço que ultrapassa as fronteiras nacionais e, como tal, demanda a adoção de métodos que possibilitem uma análise relacionada com distintas áreas jurídicas. 
Neste sentido, devem-se utilizar métodos que permitam avaliar como e em que medida há uma dialética democrática inerente à formação de uma integração entre Estados, bem como enfocar a aplicação dos postulados da participação e da governança como fundamento estruturante para o fortalecimento da democracia. Dessa forma, o método histórico possibilitará analisar como se deu a evolução dos programas e das instituições criadas para incrementar o nível e a qualidade da participação popular no âmbito dos processos integracionistas europeu. Também o método indutivo permitirá enfocar como a governança deve ser compreendida num espaço integrado de entes estatais cujas bases normativas possuem certa identidade.

Ainda no que tange a vertente teórico-metodológica, planeja-se seguir uma linha críticometodológica, que:

Supõe uma teoria crítica da realidade e sustenta duas teses de grande valor para o repensar da Ciência do Direito e de seus fundamentos e objeto: a primeira defende que o pensamento jurídico é tópico e não dedutivo, é problemático e não sistemático. Essa tese trabalha com a noção de razão prática e de razão prudencial para o favorecimento da decisão jurídica. A segunda tese insere-se na versão postulada pela teoria do discurso e pela teoria argumentativa. Essa linha compreende o Direito como uma rede complexa de linguagens e de significados. (GUSTIN; DIAS, 2006, p. 41)

Finalmente, se, num primeiro momento, a concepção de governança pode entenderse a partir de um sentido "elástico" e plurissignicativo, não se deve menosprezar uma análise voltada para a determinação das premissas necessárias para que o regime adotado pelos Estados, principalmente no plano regional, possa ser considerado ou não amplamente participativo e, por via colateral, democrático. Obviamente que tal concepção volta-se para novos paradigmas que, apesar de não alterarem obrigatoriamente a estrutura fundamental do Estado, supõe, pelo menos, uma nova roupagem e interpretação da própria democracia ao aplicar-se num espaço multidimensional.

\section{UMA ANÁliSE DA GOVERNANÇA A PARTIR DA MULTIPLICIDADE DE CONCEITOS E A INTEGRAÇÃO ESTATAL}

$\mathrm{Na}$ atual sociedade internacional globalizada, marcada pela interdependência econômica e por crescentes avanços tecnológicos e informacionais, o tema da governança global e os sistemas institucionais criados no bojo de processos de integração estatal assumem especial relevo. Em meio a uma pluralidade de atores internacionais públicos e privados capazes de estabelecer relações e contrair obrigações, complexos problemas jurídicos podem exigir estudos mais aprofundados, de modo a adequar e instituir normas em consonância com as demandas da realidade social.

Mais do que enfrentar questões clássicas que perpassam aspectos do Direito Internacional e do Direito Administrativo, como o estudo das organizações internacionais e suas respectivas funcionalidades, por exemplo, mostra-se imprescindível analisar também o processo de tomada de decisão a partir de um viés intrinsecamente vinculado aos conceitos de governança em espaços multidimensionais criados justamente por novos arranjos institucionais advindos das relações interestatais. Um viés possível de investigação destes fenômenos reside nos estudos a respeito da efetividade das decisões tomadas por tais arranjos e sua implicação na boa gestão pública dos Estados que participam de processos de integração estatal.

A governança global como resultado direto da chamada sociedade global caracteriza-se, conforme Gonçalves (2011), por quatro aspectos básicos: i) a instrumentalidade 
inerente à concepção de governança, haja vista considerá-la como instrumento capaz de solucionar, ainda que de modo fragmentado, heterogêneo e parcial, os problemas decorrentes da sociedade global (pense-se, por exemplo, nas questões ambientais transfronteiriças ou em movimentos de capital transnacionais); ii) o alargamento da participação de distintos atores no processo de adoção e consolidação dos marcos regulatórios internacionais (organizações nãogovernamentais, empresas multinacionais, etc.); iii) a solução dos problemas por vias consensuais e não exclusivamente coercitivas; e iv) a institucionalidade dos meios de decisão mediante a criação de estruturas e sistemas próprios de tomada de decisões que podem contar, em certa medida, com a participação da sociedade civil.

Este último aspecto será abordado no presente trabalho, especialmente no que tange à participação da sociedade civil, como elemento para o fortalecimento da governança e os efeitos dela derivados a partir da boa gestão pública, enquanto aspecto inerente ao desenvolvimento de práticas mais democráticas da gestão dita social, concertada e sua correlação com a salvaguarda da paz.

A definição teórica e prática do conceito de governança foi desenvolvida ao longo das décadas dos anos 60-90 subsistindo, entretanto, constantes revisões das suas principais características. Qual seria o conceito atualmente adotado para a governança? Um dos conceitos mais difundidos e utilizados pelos estudiosos está intrinsecamente relacionado com a conceituação dada pelo Banco Mundial, comumente chamada good governance. A definição proposta por esta organização defende a governança desde uma perspectiva instrumental, não avançando num sentido estratégico mais aprofundado, como pode ser visto no documento preparado pelo Banco.

Além disso, em geral, a doutrina distingue entre a governança nacional e governança global, esta última ligada aos parâmetros das transformações havidas no cenário mundial. Para a Comissão de Governança Global a definição parte de uma visão mais ampla, fortemente ancorada no empoderamento da sociedade civil:

Governança é a soma das muitas maneiras dos indivíduos e das instituições, públicas e privadas, gerirem os assuntos comuns. É um processo contínuo através do qual os interesses conflitantes ou diversos podem ser acomodados e uma ação cooperativa pode ser concretizada. Inclui instituições e regimes para fazer cumprir os regimes formais, bem como arranjos informais quer com as pessoas quer com as instituições, que tenham concordado com seus interesses. (...) No âmbito global, a governança foi considerada principalmente como relação Intergovernamental, mas deve agora ser entendida como envolvendo também organizações não-governamentais (ONG), movimentos de cidadãos, corporações multinacionais e do mercado de capitais global. Interagindo com estes são meios de comunicação globais de influência largamente aumentada. (tradução nossa) (COMISSÃO SOBRE GOVERNANÇA GLOBAL, 1996)

A definição de governança dada pela Comissão é abrangente. E não por outra razão senão a identificação de diversos problemas da sociedade atual, enquanto componente principal de agrupamentos supraestatais, com a falta de instrumentos efetivos de garantia da participação e influência dos cidadãos. Destacou-se ainda que a Governança Global não se atem apenas aos interesses de atores globais: na verdade, o cidadão e o seu bem estar será sempre o fim último de organizações nacionais, internacionais e de todo e quaisquer tipos de associações interestatais. 


\title{
2. A GOVERNANÇA NA UNIÃO EUROPEIA: DO LIVRO BRANCO AO TRATADO DE LISBOA
}

A União Europeia adotou o Livro Branco sobre governança onde expõe-se como conceito de governança "a capacidade das sociedades para dotar-se de sistemas de representação, de instituições, de processos e de corpos sociais, como instrumento de controle democrático, de participação nas decisões e de responsabilidade coletiva" (COMISSÃO EUROPEIA, 2001, p. 3).

Nesse sentido:

\begin{abstract}
A iniciativa da "governança" inscreve-se no fundo da preocupação da Comissão Europeia sobre a sua posição no sistema em análise, a compreensão inevitável sobre a renovação do método comunitário a sustentar a concepção de um reflexo específico da união de Estados e povos forjadas pelo processo de integração supranacional, o que, por si só, combina: i) a negociação entre os Estados, ii) a expressão da vontade popular e iii) e o funcionamento de instituições fortes e permanentes. ${ }^{1}$ (tradução nossa) (ALFONZO, 2004, p. 31)
\end{abstract}

Sinalizou-se ainda a relação intrínseca entre os resultados da adoção de modelos de governança e a legitimidade das decisões das instituições supranacionais (BAR CENDÓN, 2001). Bastante maculada se torna esta última se os instrumentos de controle e participação não logram alcançar os objetivos esperados por seus destinatários (RICHMOND, 2010). Nesse exato sentido, foi proposto por meio do Livro Branco:

Uma abertura do processo de elaboração das políticas da União Europeia para que mais pessoas e mais organizações estejam envolvidas na sua concepção e realização. Promove uma maior abertura e responsabilização de todos os envolvidos. Os cidadãos ficarão assim em melhores condições para compreender a forma como os Estados-Membros, atuando em conjunto na União, podem dar uma resposta mais eficaz às suas preocupações. (COMISSÃO EUROPEIA, 2001, p.3)

No Livro Branco (2001), a Comissão apresentou quatro eixos principais de mudança, quais sejam, maior participação e maior abertura; melhoria das políticas da União, à qual necessariamente seguem regulamentações bem elaboradas e otimização dos resultados; governança global; redefinição das atribuições das instituições da UE.

$\mathrm{O}$ documento, ao apresentar os objetivos específicos do eixo maior participação $e$ abertura, deixa claro o reconhecimento por parte da Comissão da deficiência de representatividade até então perpetrada pelas práticas integracionais. Destacam-se os dois seguintes escopos:

É necessária uma maior interação com os governos regionais e locais e com a sociedade civil. Esta responsabilidade incumbe principalmente aos EstadosMembros mas, por seu turno, a Comissão: - Estabelecerá um diálogo mais sistemático e numa fase precoce de elaboração de suas políticas, com os representantes dos governos regionais e locais, através das associações nacionais e europeias. - Introduzirá uma maior flexibilidade nas regras de

\footnotetext{
${ }^{1}$ No original: La iniciativa de la «gobemanza» se inscribe, sobre el trasfondo de la preocupación de la Comisión Europea sobre su propia posición en el sistema sujeto a reconsideración, en la comprensión inevitable por ésta de la renovación del método comunitario y para sostener la concepción de éste como reflejo específico de la unión de Estados y pueblos fraguada por el proceso de integración supranacional, que, por ello mismo, combina i) la negociación entre los Estados, ii) la expresión de la voluntad popular y iii) el funcionamiento de instituciones fuertes y permanentes.
} 
execução da legislação comunitária, que tome em consideração as condições regionais e locais. (grifos nossos) (COMISSÃO EUROPEIA, 2001, p. 4)

Exemplificando, um dos maiores empecilhos à implementação de determinadas medidas em países pós-conflitos é exatamente a relação de verticalidade entre orquestradores de soluções e seus destinatários (KOHLER-KOCH, 2003). Foi também o que ocorreu durante muitos anos na União Europeia. A crescente harmonização jurídica, política e econômica dos Estados Membros não homogeneizará a sociedade europeia. Por isso, identificou a Comissão a imprescindibilidade de se aproximar dos governos regionais e locais, e não apenas dos nacionais, a fim de potencializar os efeitos das decisões e medidas supranacionais.

E tal aproximação, segundo a Comissão, não pode ocorrer a qualquer momento, ao belprazer dos gestores europeus. Deve ser ela apriorística, antes mesmo da formulação das políticas integracionais. Tal afirmação traz para a linha de frente aqueles mais afetados pelas medidas levadas a cabo pelas instituições da União Europeia: os cidadãos europeus.

Em estudo publicado pelo Departamento de Direito do Instituto Universitário Europeu em 2002, apresentou-se a opinião alemã sobre a maior necessidade da participação da sociedade civil, apontada como medida primordial pela Comissão no Livro Branco sobre a governança na União Europeia. Apesar de reconhecer a importância de dar voz às necessidades dos cidadãos e grupos de interesses, asseverou o governo alemão que:

O fato de eles (cidadãos e grupos de interesses) estarem envolvidos em processos de tomada de decisões na Comunidade não os dá nenhuma legitimidade independente ou suplementar. Consultar a "sociedade civil" antes de tomar decisões pode tornar a ação da UE mais transparente e efetiva, mas o fato de os representantes de tais grupos de interesses não possuírem mandato democrático eleitoral e não estarem sujeitos à supervisão parlamentar - o interesse público sendo representado pelos Parlamentos - advoga contra eles estarem envolvidos nas decisões ou serem dados a responsabilidade por sua implementação. (JOERGES; LADEUR; ZILLER, 2002, p. 23)

A legitimidade da influência de indivíduos e grupos de interesses em instâncias executivas na União Europeia pode, de fato, ser discutida. Porém, sua superação não passa pela redução do papel dos cidadãos europeus, mas sim pelo incentivo à participação nos grupos e instâncias de controle e decisão.

Quanto às disposições do Livro Branco (2001), importante elencar finalmente os cinco Princípios da Boa Governança, que, segundo a Comissão, constituem pedra angular para a implementação de um modelo de governança mais democrático e adequado aos anseios de crescente integração dos Estados-Membros. São eles: abertura, participação, responsabilização, eficácia e coerência.

Quanto à abertura, aponta-se a exigência de as instituições realizarem suas atividades de maneira mais transparente, a partir de estratégias de comunicação com os cidadãos europeus, levando ao seu conhecimento o real significado das políticas, programas e planos da União (SCHMITTER, 2001). Em relação à participação, vislumbra-se a ampliação da presença dos destinatários das medidas supranacionais, ou seja os cidadãos, desde sua concepção até a fase executória, por meio, por exemplo, de observatórios criados e geridos por grupos de interesses, organizações não-governamentais, agrupamento de empresários, associações públicas e privadas, entre outros. Além de participar do processo de tomada de decisões, eles podem fiscalizar a efetividade da participação por intermédio dos pareceres e estudos emitidos pela Comissão.

A responsabilização diz respeito à redefinição das atribuições das instâncias executivas e legislativas. À clareza dos encargos pelas instituições europeias, segue inarredável assunção de obrigações por parte dos Estados-Membros. Já a eficácia é traço que deve marcar as políticas no 
âmbito europeu e que deve levar em consideração os potenciais impactos futuros. Além disso, o êxito das medidas supranacionais depende da aplicação de critérios de proporcionalidade: "um passo maior que a perna" pode causar lesões irreparáveis aos objetivos estipulados a longo prazo.

Por fim, a coerência exige que as políticas sejam coerentes e compreensíveis ao público em geral. Inexiste dúvida de que é esse o Princípio da Boa Governança mais difícil a ser alcançado. E dessa forma o é porque a ampla e crescente plêiade de funções requer um esforço hercúleo das instituições da União Europeia quanto à harmonia de seu discurso. Explica-se: a divisão de atribuições entre as instituições do sistema integracional europeu é mero artefato jurídico-institucional que visa a facilitar a execução das políticas europeias. Na verdade, a complexidade e dinamicidade da rede de ações levadas a cabo no âmbito supranacional ocasiona uma necessidade primeira em aproximar as ações dos dirigentes da própria União e dos Estados membros. Não se pode conceber a Comissão Europeia fomentando a flexibilização do controle de fronteiras pelos Estados membros e o Tribunal de Justiça da União Europeia agindo em sentido diametralmente oposto, tornando determinada política adotada pelas instituições legislativas e executivas (Conselho e Parlamento, por um lado, e Comissão, por outro) totalmente inócua.

\subsection{A governança e sua previsão nos Tratados fundacionais}

Em 1957 é assinado o Tratado instituindo a Comunidade Econômica Europeia (CEE), que alargou consideravelmente o escopo de relação entre os Estados membros quando comparado à CECA. Todavia, em termos de desenvolvimento da ideia de governança não se notou nenhum avanço considerável.

Destaca-se a criação de uma comissão de controle, responsável pela verificação das finanças da comunidade. Se, por um lado, tal medida não teve o desiderato de garantir nenhum tipo de participação mais ampla, por outro, a atenção à gestão financeira da então CEE pode ser tida como um sinal de que era necessário otimizar o uso de recursos financeiros comunitários:

Artigo 206. As contas da totalidade das receitas e despesas do orçamento são examinadas por uma comissão de controle, formada de comissários em contas garantidas todas as garantias de independência, e presidida por um deles. (...) A verificação, que ocorre sobre documentos e se necessário in locu, tem por objetivo constatar a legalidade e a regularidade das receitas e despesas e de assegurar uma boa gestão financeira. A comissão de controle estabelece, após o término de cada exercício, um relatório que ela adota pela maioria dos membros que a compõe. ${ }^{2}$ (tradução nossa) (COMUNIDADE ECONÔMICA EUROPEIA, 1957, p. 144)

O Tratado de Bruxelas, assinado em 1965, também denominado de Tratado de Fusão, foi responsável pela unificação das três instituições que já funcionavam a nível supranacional: a Comunidade Europeia do Carvão e do Aço, a Comunidade Econômica Europeia e a Comunidade Europeia da Energia Atômica. Não houve inovações quanto à governança. Ocorreu apenas a unificação das comissões de controle das três comunidades, apesar de somente o Tratado da CEE prever tal instituição de forma expressa:

Artigo 22. É instituída uma comissão de controle das Comunidades europeias. Essa comissão de controle substitui as comissões de controle da Comunidade

\footnotetext{
${ }^{2}$ No original: Article 206. Les comptes de la totalité des recettes et dépenses du budget sont examines par une comission de controle, formée de comissaires aux comptes offrant toutes garanties d'indépendance, et présidée par l'un d'eux. (...) La vérification, qui a lieu sur pièces et au besoin sur place, a pour objet de constater la légalité et la régularité des recettes et dépenses et de s'assurer de la bonne gestion financière. La commission de contrôle établit, après la clôture de chaque exercice, un rapport qu'elle adopte à la majorité des membres qui la composent.
}

Revista de Direito Brasileira | São Paulo, SP | v. 15 | n. 6 | p. 03 - 19 | set./dez. 2016 
europeia do carvão e do aço, da Comunidade econômica europeia e da Comunidade europeia da energia atômica. ${ }^{3}$ (tradução nossa) (COMUNIDADE EUROPEIA DO CARVÃO E DO AÇO; COMUNIDADE ECONÔMICA EUROPEIA; COMUNIDADE EUROPEIA A ENERGIA ATÔMICA, 1965, p. 9)

Em seguida, o Tratado de Maastricht, ou Tratado da União Europeia, assinado em 1992, representou o maior passo dado rumo à integração política dos Estados membros, com a remodelação de diversas instituições supranacionais. Já no início do referido Tratado, em suas Disposições Comuns, dispõe-se acerca de um anseio por maior proximidade das instituições da União com o cidadão europeu:

Artigo A. (...) O presente Tratado assinala uma nova etapa no processo de criação de uma união cada vez mais estreita entre os povos da Europa, em que as decisões serão tomadas ao nível mais próximo possível dos cidadãos. (UNIÃO EUROPEIA, 1992, p. 7)

Não obstante, não foram prestigiados a participação e o controle dos indivíduos ou grupos representativos de interesses no Tratado de Maastricht. O que há são previsões que garantem a eleição de representantes na instituição legislativa e nos órgãos sociais, o direito de petição junto às instituições da União. Contudo, não se detalham instrumentos efetivos de governança.

O Tratado de Amsterdã, assinado em 1997, alterou algumas disposições do Tratado da União Europeia, visando, essencialmente, preparar a União para a entrada de novos Estados membros. Uma vez mais, o tema governança não é alvo de grandes deliberações. Contudo, interessante notar que o artigo acima citado foi alterado, passando a vigorar com a seguinte redação:

Artigo A. (...) O presente Tratado assinala uma nova etapa no processo de criação de uma união cada vez mais estreita entre os povos da Europa, em que as decisões serão tomadas de uma forma tão aberta e ao nível mais próximo possível dos cidadãos. (grifo nosso) (UNIÃO EUROPEIA, 1997, p. 7)

Procurou-se democratizar o processo de tomada de decisões, tornando-o mais acessível aos cidadãos. Aponta-se como exemplo o Protocolo relativo à aplicação dos princípios da subsidiariedade e da proporcionalidade. Neste, são feitas várias declarações dos Estados partícipes referentes a diversos aspectos de tais cânones interpretativos aplicáveis a todas as instituições da União Europeia (Executivo, Legislativo e Judiciário, nas formas pelas quais se manifestam), dentre as quais sobressalta:

9. Sem prejuízo do seu direito de iniciativa, a Comissão deve: - salvo em casos de especial urgência ou que exijam confidencialidade, proceder a amplas consultas antes de propor textos legislativos e, quando adequado, publicar documentos relativos a essas consultas. (grifo nosso) (UNIÃO EUROPEIA, 1997, p. 107)

Nota-se que a instituição responsável pela execução das políticas da União e propositura de leis supranacionais, ou seja a Comissão, deve, via de regra, realizar consultas de forma ampla.

\footnotetext{
${ }^{3}$ No original: Article 22. Il est institué une commission de contrôle des Communautés européennes. Cette commission de contrôle se substitue aux commissions de contrôle de la Communauté européenne du charbon et de l'acier, de la Communauté économique européenne et de la Communauté européenne de l'énergie atomique.
}

Revista de Direito Brasileira | São Paulo, SP | v. 15 | n. 6 | p. 03 - 19 | set./dez. 2016 
Isso quer dizer que não se restringiu, pelo menos no Tratado, a participação dos indivíduos e grupos de interesse, estejam ou não eles previamente designados para tal função.

Seguindo a cronologia dos conjuntos normativos modificadores do Tratado da União Europeia, tem-se o Tratado de Nice, assinado em 2001, mesmo ano da feitura do Livro Branco sobre a governança europeia. O referido Acordo pormenorizou a estrutura da Justiça da União e adequou algumas disposições à entrada de novos membros. Em relação ao aperfeiçoamento da governança na União, foi instituído um Comitê Econômico e Social, a partir da alteração do art. 257 do Tratado da União Europeia:

Artigo 257. ${ }^{\circ}$ É instituído um Comitê Econômico e Social, de natureza consultiva. O Comitê é composto por representantes das diferentes componentes de caráter econômico e social da sociedade civil organizada, designadamente dos produtores, agricultores, transportadores, trabalhadores, comerciantes e artífices, das profissões liberais, dos consumidores e do interesse geral. (grifo nosso) (UNIÃO EUROPEIA, 2001, p. 26)

Inexiste dúvida de que foi a primeira vez em que um ato normativo de tal envergadura previu a participação efetiva de setores da sociedade civil organizada. Aperceberam-se as instituições da União que os meios de controle em relação a seus processos decisórios e executivos estavam defasados, desconsiderando sobremaneira o direito de participação e influência dos cidadãos nos rumos da integração europeia. Além disso, verificou-se também que formas ortodoxas de representatividade não eram instrumentos suficientes à legitimidade democrática no contexto integracional. E dessa forma o é em virtude do caráter singular da construção da União Europeia, especialmente em sua vertente multidimensional (Castillo e Castillo, 2016) e supranacional.

Apesar disso, foi apenas com o Tratado de Lisboa, assinado em 2007, com entrada em vigor em 2009, que os instrumentos e formas de garantia da governança na União ganharam destaque nos debates antes da confecção do referido instrumento, aparecendo, por conseguinte, diversas vezes em suas disposições. Importante apontar que a palavra "governança" apareceu pela primeira vez no Tratado da UE devido a alterações feitas pelo Tratado de Lisboa.

Inseriu-se o artigo 16-A no Tratado da União Europeia, segundo o qual:

1. A fim de promover a boa governança e assegurar a participação da sociedade civil, a atuação das instituições, órgãos e organismos da União pauta-se pelo maior respeito possível do princípio da abertura. 2. As sessões do Parlamento Europeu são públicas, assim como as reuniões do Conselho em que este delibere e vote sobre um projeto legislativo. (UNIÃO EUROPEIA, 2007, p. 50)

Além dessa alteração, o Comitê Econômico e Social teve sua composição pluralizada e seu escopo substancialmente aumentado, por meio da inserção do art. 256-A ao Acordo da União. Por meio desse mesmo dispositivo, também foi alterada a forma de instituição e formação dos Comitês das Regiões:

Art. 256. ${ }^{\circ}$-A 1. O Parlamento Europeu, o Conselho e a Comissão são assistidos por uma Comitê Econômico e Social e por um Comitê das Regiões, que exercem funções consultivas. $\quad 2$. O Comitê Econômico e Social é composto por representantes das organizações de empregadores, de trabalhadores e de outros atores representativos da sociedade sócia, em especial nos domínios socioeconômico, cívico, profissional e cultural. 3. O Comitê das Regiões é composto por representantes das autarquias regionais e locais que sejam quer titulares de um mandato eleitoral a nível regional ou local, quer politicamente responsáveis perante uma assembleia eleita. 4. Os membros do Comitê 
Econômico e Social e do Comitê das Regiões vinculados a quaisquer instruções. Exercem as suas funções com total independência, no interesse geral da União. (grifo nosso) (UNIÃO EUROPEIA, 2007, p. 118)

$\mathrm{O}$ artigo acima responde a diversas críticas historicamente apontadas pela doutrina em relação aos instrumentos de participação e controle da governança na União Europeia. Primeiramente, o redimensionamento das funções do Comitê das Regiões (MATA DIZ, 2005), antes com pouca ou quase nenhuma influência no processo decisório, aproximando as instituições supranacionais da realidade local, vez que compostos por representantes dos entes subnacionais ou locais. A formação dessa instituição consultiva enfraquece aqueles que suspeitavam da legitimidade para influenciar e exercer controle sobre as decisões tomadas em âmbito supranacional: sendo seus titulares detentores de mandato eleitoral, ou responsáveis políticos perante determinada assembleia eleita, tornam-se de fato "a voz direta" dos indivíduos e grupos de interesses.

Por fim, mas não menos importante, a independência de atuação dos Comitês desalinhou de vez os interesses de cidadãos europeus dos de seus países de origem, rompendo com uma tradição de escolha dos membros de Comitês por representantes dos governos nacionais, iniciada pelo Tratado de instituição da Comunidade Europeia do Carvão e do Aço de 1951.

\subsection{A influência da governança na conformação da institucionalidade europeia}

A questão da governança e seu tratamento pelas instituições e órgãos europeus inicia-se com o Parecer do Comitê das Regiões sobre "O papel e a participação do Comitê das Regiões no processo de tomada de decisão comunitário". Tal documento, publicado em 03.05.2002, com data, portanto, posterior à do Livro Branco da Comissão Europeia sobre a governança europeia, extraiu do mesmo sua inspiração. Nas primeiras considerações de tal Parecer, o Comitê aponta que:

1.3. Está convicto de que o debate sobre o futuro da Europa não pode limitar-se a um mero debate institucional ou a uma discussão sobre competências e financiamento. Antes entende que as atribuições da União Europeia e a delimitação de competências entre os Estados-Membros e os órgãos do poder local e regional devem basear-se e reger-se pelo princípio da subsidiariedade, da limitação de competências, da proporcionalidade e, também, da obrigação de respeitar a identidade nacional; que daí devem advir maior transparência e uma maior responsabilização dos implicados, assim como um processo de decisão mais eficiente e democrático com vista a uma política que ofereça o máximo valor acrescentado e promova a participação dos cidadãos. (grifos nossos) (UNIÃO EUROPEIA, 2002, p. 41)

Durante muitos anos, a União Europeia, personificada em suas diversas instituições, pareceu estar encapsulada em sua própria realidade, fazendo valer seus próprios interesses. Tal modus operandi institucional a afastava dos cidadãos europeus. É por isso que, no trecho acima citado do Parecer do Comitê das Regiões, aponta-se a necessidade de as discussões levadas a cabo pelas autoridades supranacionais extrapolarem o binômio competências e financiamento. Levar em consideração os indivíduos, os grupos de interesses que podem formar, criar normas para fomento do controle e participação dos cidadãos; esse é o meio de legitimar as políticas integracionais, como deixa evidente o segundo trecho em negrito do Parecer.

O Comunicado 277 de 2002 da Comissão Europeia, inspirado pelas disposições do Livro Branco sobre a governança europeia, propõe os princípios gerais e regras mínimas de consulta das partes interessadas. Interessante iniciativa foi a criação do sítio Web CONECCS (Consulta, 
Comissão Europeia e sociedade civil), responsável pela reunião de

Dados sobre órgãos consultivos formais e estruturados. O objetivo consiste em informar sobre comitês e outras estruturas da Comissão através das quais as organizações da sociedade civil são consultadas formal ou estruturadamente. (UNIÃO EUROPEIA, 2002, p. 8)

Conforme se pode observar, o endereço eletrônico correspondente à iniciativa CONECCS foi substituído pelo site da Transparência da Comissão Europeia ${ }^{4}$. Não resta dúvida de que a própria existência de um Comitê consiste no primeiro passo da participação efetiva e controle democrático. Por mais óbvio que seja, repisa-se que, antes mesmo de atuar junto a qualquer instituição, é imprescindível notar a sua existência no mundo real e o seu efetivo papel na realidade fática.

Após o lançamento do Livro Branco sobre a Governança Europeia, no final de 2002, emitiu-se um "Relatório da Comissão sobre a governança europeia", no qual foram especificadas ações a serem implementadas quanto à participação e controle dos cidadãos europeus nas instituições europeias, assim como apresentados os resultados de uma Consulta Pública, também proposta inicialmente por aquele. Segundo o Relatório, tal instrumento de perquirição do ponto de vista popular acerca dos postulados do Livro Branco considerou como fundamentais as seguintes perspectivas de governança:

Reforçar a participação numa perspectiva ascendente (bottom-up) na concepção e aplicação das políticas da UE; alargar a paleta de instrumentos disponíveis para dar resposta aos novos desafios da governança; e recentrar a missão das instituições europeias, dotando-as de responsabilidades mais claras. (UNIÃO EUROPEIA, 2002, p. 8)

Em 2003, a Comissão publicou uma "Comunicação da Comissão ao Conselho, ao Parlamento Europeu e ao Comitê Econômico e Social Europeu", com o título "Governança e Desenvolvimento". Nessa, talvez pela primeira vez em sua história, uma instituição da União Europeia define precisamente o que para esta significa a governança:

Governança significa a capacidade do Estado de servir os cidadãos. (...) A governança diz respeito às regras, processos e comportamentos segundo os quais são articulados os interesses, geridos os recursos e exercido o poder na sociedade. O modo como são desempenhadas as funções públicas, geridos os recursos públicos e exercidos os poderes públicos regulamentares constituem os principais aspectos a ter em conta neste contexto. $\mathbf{O}$ verdadeiro valor do conceito de governança reside no fato de ser terminologicamente mais pragmática do que outros termos tais como 'democracia', 'direitos humanos', etc (grifos nossos) (UNIÃO EUROPEIA, 2003, p. 3)

Por meio do conceito acima, enfraqueceu-se a crítica usual de que "governança" era um fenômeno por demais abstrato, ou até mesmo confundível com os de "democracia" ou "direitos humanos". Na verdade, aponta a Comissão que é exatamente o viés pragmático da governança sua característica precípua o que a distingue de outras concepções adotadas conforme analisado alhures. Deve a governança ser posta em prática de uma forma objetiva e palpável.

Pouco tempo depois, em 2004, o Parlamento Europeu emite uma "Resolução sobre a governança na política e desenvolvimento da União Europeia”. Com efeito, tratou-se de uma

${ }^{4}$ Trata-se do seguinte endereço eletrônico: http://ec.europa.eu/transparency/civil_society/index_en.htm (Acesso em 18 de junho de 2016).

Revista de Direito Brasileira | São Paulo, SP | v. 15 | n. 6 | p. 03 - 19 | set./dez. 2016 
resposta positiva de outra instituição da UE ao Comunicado da Comissão acima referido. Assim sendo, o Parlamento:

2. Acolhe favoravelmente a posição assumida pela Comissão segundo a qual a governança se deve caracterizar pelo diálogo e pelo reforço da capacidade institucional; (...) 6. Solicita à Comissão que garanta o seguimento da Comunicação sobre governança e desenvolvimento, a fim de desenvolver e operacionalizar os princípios, transformando-os em orientações (...); 7. Considera as várias possibilidades apresentadas na referida Comunicação da Comissão como um bom enquadramento para a análise e ulterior definição de um quadro político destinado a reforçar a coerência entre as abordagens da CE e dos Estados-Membros em matéria de governança. (grifo nosso) (UNIÃO EUROPEIA, 2004, p. 552)

Se dentro de apenas um Estado a coerência entre suas instituições já é dificilmente alcançada, o que dizer então das instituições da União Europeia. Uma composição heterogênea das autoridades supranacionais é essencial, e até mesmo imprescindível, tendo em vista a diversidade de modelos políticos e econômicos dos Estados membros. Isso é verdade. porém, a cooperação entre as instituições do sistema europeu e a harmonia entre suas ações deve acontecer. Sendo tal o desiderato, uma forma bastante utilizada é esta: edição de instrumentos jurídicos que afinam o discurso.

Nesse sentido, aponta-se o princípio do equilíbrio institucional, interessante paradigma axiomático adotado desde o acórdão proferido pelo então Tribunal de Justiça da Comunidade Europeia do Carvão e do Aço no caso Meroni vs. Alta Autoridade da Comunidade Econômica do Carvão e do Aço de 1958, como corolário do sistema de repartição das competências das instituições da União Europeia. Segundo esse princípio, as instituições do sistema europeu devem atuar estritamente no âmbito das atribuições que lhes são outorgadas pelos tratados, não adentrando em searas de atuação cuja competência lhe falta.

Em 2006, por meio da Resolução sobre uma estratégia de simplificação do quadro regulamentar, o Parlamento Europeu analisa a regulação sobre a participação da sociedade civil, ao considerar que tal simplificação poderia causar redução desta:

25. Considera que o recurso à normalização pode levar a uma redução da transparência e da responsabilidade, porquanto os representantes eleitos são excluídos da tomada de decisões e os direitos de participação das organizações não-governamentais e de outras partes envolvidas não são garantidos de forma homogênea; considera, por conseguinte, que a normalização deve limitar-se estritamente às medidas de harmonização de índole puramente técnica. (grifos nossos) (UNIÃO EUROPEIA, 2006, p. 49)

\section{A APLICAÇÃo dOS POSTUlados da GOVERNANÇA PELO TRIBUNAL DE JUSTIÇA DA UNIÃO EUROPEIA: O CASO DO GLIFOSATO E O DIREITO DE PARTICIPAÇÃO}

O fenômeno da governança, e por extensão sua modalidade na União Europeia, não é temática pontual de aparecimento exato na jurisprudência dos Tribunais. Na verdade, trata-se de forma de garantia de controle e participação de indivíduos e coletividades nas mais diversas instituições do poder político, seja público ou privado. Cuida-se, assim sendo, da análise do posicionamento do poder judicial europeu a partir das sentenças emitidas pelo Tribunal de Justiça da União Europeia (TJUE) sobre tal temática.

Com efeito, chegou-se ao processo T-545 de 2011, cujo assunto trata de uma das vertentes 
da governança: o direito à transparência. Em 20 de dezembro de 2010, a Stichting Greenpeace Nederland e a Pesticide Action Network Europe (PAN Europe) solicitaram à Comissão da União Europeia acesso a diversos documentos referentes à primeira autorização de colocação no mercado de um determinado composto químico, o glifosato, como substância ativa. Basearam-se essencialmente no direito à informação e à participação dos cidadãos no processos de tomada de decisão, ambos direitos fundamentais para garantir a governança na União Europeia.

A Comissão encaminhou o pedido de acesso aos documentos às autoridades da República Federal da Alemanha, detentora da posse destes. As autoridades alemãs negaram acesso a um dos volumes da documentação requerida, sob a alegação de que, caso os divulgasse, feriria interesses comerciais de pessoas físicas ou jurídicas, os quais também são alvo, de modo expresso ou implícito, de proteção da normativa supranacional. $\mathrm{Na}$ verdade, o acesso aos referidos documentos pelas requerentes iria de encontro ao direito à propriedade intelectual, vez que revelavam determinada forma de gestão e processamento comercial e industrial do glifosato. Conforme atesta o acórdão do anteriormente citado processo, apontou o Secretário-Geral da Comissão que:

A divulgação das informações que constam do documento controvertido permitiria às empresas concorrentes copiar os processos de produção dos requerentes da inscrição do glifosato, o que conduziria em perdas consideráveis para elas, em violação dos seus interesses comerciais e dos respetivos direitos de propriedade intelectual. O interesse público na divulgação de informações tinha já sido tomado em consideração, porquanto os efeitos possíveis das emissões de glifosato resultavam das outras partes do projeto de relatório, tornadas públicas, designadamente no que se refere às impurezas pertinentes e aos metabolitos. Quanto às informações relativas às impurezas não pertinentes, incluídas no documento controvertido, referiam-se a elementos que não apresentam riscos para a saúde ou o ambiente, mas que levariam a revelar os processos de produção de cada produto. (grifo nosso) (TRIBUNAL DE JUSTIÇA DA UNIÃO EUROPEIA, 2013, p. 3)

É possível que tal fora a conclusão do Secretário-Geral em decorrência do lobby feito pelas empresas responsáveis pelo processamento do glifosato que teriam suas informações divulgadas ao Grande Público. Ao pormenorizar o objeto do litígio, o Juiz Relator do processo apontou que:

(a) a recusa ao acesso ao documento tinha sido feita pelas autoridades alemãs. Mesmo que a Comissão houvesse chancelado posteriormente tal decisão, importante notar que o "não" fora dado pela Alemanha, e não pela Comissão em si;

(b) as requerentes afirmaram em suas manifestações que as relações contratuais entre as diferentes empresas responsáveis pelo glifosato e seus métodos de fabricação não lhes interessavam. Na verdade, haviam solicitado ao TJUE a anulação da decisão da Comissão na medida em que se lhes recusava o acesso às informações acerca do grau de pureza da substância, sua "identidade" técnica e a quantidade de impurezas presentes nos materiais, além de outros dados do componente químico, dados esses que seriam importantes quando da verificação de seu potencial ofensivo ao meio ambiente.

(c) por fim, especificaram as demandantes o que entendem por "identidade" e quantidade de impurezas: dizem respeito ao conhecimento das outras substâncias químicas produzidas durante a fabricação do glifosato e sua quantidade.

$\mathrm{O}$ principal argumento das requerentes está relacionado à prevalência do direito à informação, como sendo de interesse público, quando em confronto com o direito à propriedade intelectual, de cunho privado. Ao analisar esse ponto, o Juiz Relator assevera que o direito à informação encontrava-se previsto no Regulamento n. 1049 de 2001 (aplicável ao glifosato), 
normativa em consonância com o espírito do Tratado de Amsterdã, corroborado pelo Tratado de Lisboa, onde se assinalava que:

Uma nova etapa no processo de criação de uma união cada vez mais estreita entre os povos da Europa, em que as decisões sejam tomadas de uma forma tão aberta quanto possível e ao nível mais próximo dos cidadãos. (...) O direito de acesso do público aos documentos das instituições está associado do caráter democrático destas. (TRIBUNAL DE JUSTIÇA DA UNIÃO EUROPEIA, 2013, p. 6)

Seguindo em seu raciocínio, afirmou que as exceções à divulgação das informações, conforme previsão do Regulamento mencionado, devem ser interpretadas e aplicadas de forma restritiva, vez que derrogadores do princípio do acesso mais amplo possível do público aos documentos (TRIBUNAL DE JUSTIÇA DA UNIÃO EUROPEIA, 2013). Mesmo quando aplicável uma das exceções à divulgação ampla de documentos, incumbe ao Estado membro o dever de analisar se há ou não um interesse público superior que exija a divulgação dos documentos. Ponderou o TJUE que outro Regulamento, o de n. 1367 de 2006, estabelecia:

Uma presunção legal segundo a qual a divulgação reveste um interesse público superior quando as informações requeridas sejam relacionados com emissões para o ambiente, exceto quando estas informações disserem respeito a um inquérito, nomeadamente o inquérito relativo a eventuais incumprimentos do direito da União Europeia. (TRIBUNAL DE JUSTIÇA DA UNIÃO EUROPEIA, 2013, p. 7)

Verificando o conteúdo do Regulamento 1367, percebe-se menção expressa a tal presunção. Porém, é de se esperar que quaisquer solicitações de informações envolvendo o manuseio de substâncias químicas revelem interesse, mesmo que tangencial, relativo a emissões para o meio ambiente. Dessa forma, justo concluir que o Juiz Relator adotou um entendimento amplo acerca do direito à informação quando este vem associado à liberação de substâncias ao meio ambiente: logo, torna-se prescindível a comprovação minuciosa acerca da necessidade dos dados. Basta relacionar as informações perquiridas às emissões ao meio ambiente, o que foi feito pelas Requerentes, sustentando que:

Os resíduos da substância ativa (glifosato) no ambiente e os seus efeitos na saúde humana estão diretamente ligados à pureza da substância, em particular à "identidade" e à quantidade de impurezas presentes no glifosato (...) No entender das recorrentes, é também importante conhecer o perfil analítico dos lotes utilizados para os controles (...) Esta é a razão pela qual a composição exata dos produtos desenvolvidos e controlados deve ser divulgada, o que permitiria determinar quais os elementos tóxicos que são emitidos para o ambiente e que nele podem permanecer certo tempo. (TRIBUNAL DE JUSTIÇA DA UNIẪO EUROPEIA, 2013, p. 4)

Em sede conclusiva, o TJUE entendeu que a decisão da Comissão, que recusou o acesso dos documentos solicitados pelas Requerentes - elaborados pelas autoridades da Alemanha contraria o direito à informação, devendo, por isso, ser anulada. Sendo o direito à informação uma das condições ao exercício dos instrumentos de governança na União Europeia, tal compreensão do TJUE, datada de 2011, imprime um caráter fundamental ao direitos de participação e por conseguinte controle do cidadão (in casu, representado por uma organização não-governamental) sobre as atividades e decisões tomadas pelas instituições europeias. 


\section{CONCLUSÃO}

A discussão sobre a governança e a participação no âmbito dos processos de integração demanda uma análise das políticas e da institucionalidade voltada para o fortalecimento da democracia, vez que os cidadãos não podem estar alijados do processo decisório que perpassa toda e qualquer tentativa de associação interestatal, especialmente aquela que implica a criação de um sistema institucional e jurídico próprio e singular, como é o caso da União Europeia.

Não cabe dúvida de que a participação da sociedade civil no processo de tomada de decisões públicas é o instrumento mais importante da democracia participativa, e só pode ser alcançado por meio do diálogo entre a sociedade e as instituições competentes para a tomada e implementação de decisões. Contudo, os próprios Estados, quando da negociação de acordos visando a uma integração mais profunda, devem estabelecer as normas e criar as instituições que garantam, efetivamente, tal participação.

Conforme visto no presente trabalho, a União Europeia desde sua criação na década de 50 vem intentando forjar um espaço de participação cidadã, objetivando fortalecer os instrumentos e meios de expressão da vontade popular, de modo a contornar o déficit democrático do qual sempre é acusada, buscando ainda aproximar, cada vez mais, os cidadãos das decisões tomadas por tais instituições.

A institucionalidade e as disposições normativas encontradas no âmbito da UE representam o resultado direto de uma preocupação voltada para a legitimidade do processo decisório comunitário, ainda que, em seu atual estágio, não tenha logrado obter efetivamente maior participação dos cidadãos, conforme apontado anteriormente.

Como o escopo do presente trabalho é realizar uma primeira aproximação sobre o tema, não se dedicou a uma análise específica de todos os instrumentos adotados para incrementar tal participação; contudo, é mister mencionar que há um esforço contínuo no sentido de aperfeiçoálos, como é o caso da proposta de iniciativa popular prevista no Tratado de Lisboa, em seu artigo 11, numeral $4^{\circ}$, complementado pelo artigo 24, parágrafo primeiro, do Tratado de Funcionamento da União Europeia.

Além disso, as tentativas de criar um Parlamento europeu com competências realmente legislativas ocorreu somente após a entrada em vigor do Tratado de Lisboa (2009), o que demonstra a necessidade de contar com mecanismos que venham a dotar o processo de legitimidade, incrementando assim o nível democrático das decisões tomadas.

Finalmente, conforme destacado alhures, não se pode olvidar que os processos de integração tem como destinatários finais os próprios cidadãos dos Estados partícipes de tais processos; portanto, não se pode simplesmente afastá-los das decisões que venham a ser tomadas, sob pena de debilitamento da governança e, de conseguinte, do valor maior da Democracia.

AGRADECIMENTO: A autora agradece ao Programa Eramus + - Cátedra Jean Monnet de Direito UFMG (565401-EPP-1-2015-1-BREPPJMO-CHAIR) pelo apoio concedido.

\section{REFERÊNCIAS BIBLIOGRÁFICAS}

ALFONZO, Luciano Parejo. Los Principios de la "Gobernanza Europea". Revista de Derecho de la Unión Europea, n. 6-1, 1ºmestre 2004.

BAR CENDÓN, Antonio. El Libro Blanco la Gobernanza Europea y la reforma de la Unión. Contribución a la Comisión sobre la Gobernanza. 2001. Disponível em http://europa.eu.int/comm/gouvernance/contrib_cendon_es.pdf., acesso em 12 abr 2005. 
COMISSÃO EUROPEIA. Livro Branco da Comissão Europeia - A Governança Europeia - 25 de julio de 2001 - COM (2001) 428 final.

GONÇALVES, Alcindo. Regimes internacionais como ações da governança global. Meridiano 47, vol. 12 , n. 125 , p. 40 a 45, mai.-jun. 2011.

GUSTIN, Miracy Barbosa de Sousa; DIAS, Maria Teresa Fonseca. (Re)pensando a Pesquisa Jurídica. 2a. Ed. Belo Horizonte: Del Rey, 2006.

JOERGES, Christian; LADEUR, Karl Heinz.; ZILLER, Jacques. Governance in the European Union and the Commission White Paper. EUI Working Paper LAW, n. 2002/8, Florence, European University Institute, Department of Law, 2002.

KOHLER-KOCH, Beate. The Evolution and Transformation of European Governance. Political Science Series, n. 58, Viena, Institute for Advanced Studies, Novembro de 1998.

MATA DIZ, Jamile Bergamaschine. Las relaciones entre la Unión Europea y el Mercosur: el reforzamiento de la participación ciudadana en el proceso de asociación birregional. In: $E l$ diálogo entre los pueblos y las culturas en el marco de las relaciones latinoamericanas.

MOLINA DEL POZO Carlos F.; FAIÑAS, Andre; MATA DIZ, Jamile B. (orgs.). Madrid: Dijusa, 2005, p. 445-476.

NAVAS CASTILLO, Antonia y Navas Castillo, Florentina. El Estado Constitucional Multinivel. Madrid: Dykinson, 2016.

RICHMOND, Oliver P. Para Além da Paz Liberal? Respostas ao "Retrocesso". Trad. de Victor Coutinho Lages. Contexto Internacional, vol. 32, n. 2, p. 297-332, julho/dezembro 2010

SCHMITTER, Philippe C. What is there to legitimize in the European Union.... and how might this be accomplished? In: Jean Monnet Working Paper No.6/01, Symposium: Mountain or Molehill? A Critical Appraisal of the Commission White Paper on Governance, disponível em http://jeanmonnetprogram.org/archive/papers/01/011401.html, acesso em 12 nov 2004.

\section{LEGISLAÇÃO}

COMUNIDADE ECONÔMICA EUROPEIA. Tratado instituindo a Comunidade Econômica Europeia, de 25 de março de 1957, disponível em: http://europa.eu/index_pt.htm, acesso em 17 de junho de 2016.

ORGANIZAÇÃO DAS NAÇÕES UNIDAS. Relatório da Comissão sobre Governança Global, 1996, disponível em http://www.gdrc.org/u-gov/global-neighbourhood/chap1.htm, acesso em 10 de junho de 2016.

UNIÃO EUROPEIA. Tratado da União Europeia, de 7 de fevereiro de 1992, disponível em: http://europa.eu/index_pt.htm, acesso em 18 de junho de 2016. 
UNIÃO EUROPEIA. Tratado de Amsterdã, de 2 de outubro de 1997, disponível em: http://europa.eu/index_pt.htm, acesso em 18 de junho de 2016.

UNIÃO EUROPEIA. Tratado da Nice, de 10 de março de 2001, disponível em: http://europa.eu/index_pt.htm, acesso em 19 de junho de 2016.

UNIÃO EUROPEIA. Parecer do Comitê das Regiões sobre "O papel e a participação do Comitê das Regiões no processo de tomada de decisão comunitário", de 14 de novembro de 2001, disponível em: http://europa.eu/index_pt.htm, acesso em 19 de junho de 2016.

UNIÃO EUROPEIA. Comunicado 277 da Comissão Europeia, de 5 de junho de 2002, disponível em: http://europa.eu/index_pt.htm, acesso em 20 de junho de 2016.

UNIÃO EUROPEIA. Relatório da Comissão sobre a Governança Europeia, de 11 de dezembro de 2002, disponível em: http://europa.eu/index_pt.htm, acesso em 20 de junho de 2016.

UNIÃO EUROPEIA. Comunicação da Comissão ao Conselho, ao Parlamento Europeu e ao Comitê Econômico e Social Europeu, de 20 de outubro de 2003, disponível em: http://europa.eu/index_pt.htm, acesso em 21 de junho de 2016.

UNIÃO EUROPEIA. Resolução do Parlamento Europeu sobre a governança na política de desenvolvimento da União Europeia, de 29 de abril de 2004, disponível em: http://europa.eu/index_pt.htm, acesso em 21 de junho de 2016.

UNIÃO EUROPEIA. Resolução do Parlamento Europeu sobre uma estratégia de simplificação do quadro regulamentar, de 16 de maio de 2006, disponível em: http://europa.eu/index_pt.htm, acesso em 21 de junho de 2016.

UNIÃO EUROPEIA. Regulamento 1367 do Parlamento Europeu e do Conselho, de 6 de setembro de 2006, disponível em: http://europa.eu/index_pt.htm, acesso em 23 de junho de 2016

UNIÃO EUROPEIA. Tratado de Lisboa, de 11 de dezembro de 2007, disponível em: http://europa.eu/index_pt.htm, acesso em 19 de junho de 2016.

\section{JURISPRUDÊNCIA}

COMUNIDADE EUROPEIA DO CARVÃO E DO AÇO. Tribunal de Justiça. Meroni vs. Alta Autoridade da Comunidade Econômica do Carvão e do Aço. Luxemburgo, 13 de junho 1958, disponível em http://europa.eu/index_pt.htm, acesso em 19 de junho de 2016.

UNIÃO EUROPEIA . Tribunal de Justiça. Stichting Greenpeace Nederland e a Pesticide Action Network Europe (PAN Europe) vs. Comissão Europeia. Luxemburgo, 8 de outubro de 2013., disponível em http://europa.eu/index_pt.htm, acesso em 22 de junho de 2016. 